Open Access

\title{
Customer satisfaction of Vietnam Airline domestic service quality
}

\author{
Giao Ha Nam Khanh
}

Correspondence:

khanhgiaohn@yahoo.com

University Finance Marketing, 2C

Pho Quang Street, Ward 2, Tan Binh

District, HoChiMinh City, Vietnam

\begin{abstract}
The paper examines the relation between Vietnam Airline domestic service quality and customer satisfaction by gathering opinions from 402 passengers employing the Skytrax scale with some modification along with Cronbach's alpha, exploratory factor analysis, and multiple regression analysis. Results show that Vietnam Airline domestic service quality can be measured by the following six determinants in order of decreasing importance: (1) boarding/deplaning/baggage, (2) check-in, (3) in-flight services, (4) reservation, (5) aircraft, and (6) flight crew. All of them have directly proportional effects to customer satisfaction. The paper also offers some suggestions to improve the service quality, thereby enhancing the customer satisfaction.
\end{abstract}

Keywords: Customer satisfaction, Domestic service, Service quality, Vietnam Airline

\section{Background}

In the past few years, air transport has gained high growth rates. IATA reports showed that air transport of passengers in 2015 rose by 7.4\%; this was the greatest increase since the rebound from the depth of the global financial crisis in 2010 and well above the long-run average of $5.5 \%$.

According to the 2016 Report by Civil Aviation Authority of Vietnam, the air transport business served 52.2 million passengers, increasing by $29 \%$ in 2015 , in which 28 million are domestic passengers, increasing by $30 \%$ in 2015. Additionally, 52 foreign airlines are operating 78 routes from 28 countries or territories to Vietnam. Domestic services offered by local airlines comprise 50 routes from three hubs-HaNoi, DaNang, and HoChiMinh City-to 17 local airports. The biggest market shares of this business are held by Vietnam Airline (VNA), VietJet Air, and Jetstar Pacific Airline. The data show that air transport is a potential and promising market. Local airlines and VNA in particular are facing great challenges and keen competition from foreign rivals.

According to Skytrax [18], VNA is only ranked as a three-star service on a five-star scale. This means that VNA service quality is at a medium level and it should make great effort to improve its service quality. When VNA joined Skyteam on June 10, 2010, use of the Skytrax ranking scale is necessary and also an objective of this research.

To retain its stability and competitiveness in such a global dynamic market, VNA should put a major emphasis on service quality in order to gain the highest level of passenger satisfaction. According to Aksoy et al. [1], passenger satisfaction is one of

(c) The Author(s). 2017 Open Access This article is distributed under the terms of the Creative Commons Attribution 4.0 International License (http://creativecommons.org/licenses/by/4.0/), which permits unrestricted use, distribution, and reproduction in any medium, provided you give appropriate credit to the original author(s) and the source, provide a link to the Creative Commons license, and indicate if changes were made. 
the most critical factors in the airline industry and regarded as playing a crucial part in guaranteeing the business success in today's competitive world. This research aimed at (1) identifying the key determinants that effect directly to local passenger satisfaction of VNA, (2) measuring the direct effects on local passenger satisfaction of VNA, and (3) recommending suggestions for the company to better off its field based on the results and findings of the research.

This paper includes five parts. Part 1 introduces the pivotal point of departure for the paper which is the problem that seeks to be solved. The problem statement is generated by the preceding problem identification which fits the purpose of identifying the specific research objective at hand. Subsequently, part 2 discusses the theoretical area and instruments applied to answer the problem at hand, which are founded in the nature of service quality and customer satisfaction, and rise to a research model. Part 3 encompasses the methodological considerations applied to answer the posed research questions. The analysis in part 4 covers the actual statistical data analysis which processes and examines the data gathered from the questionnaire and states out the findings. Part 5 summarizes the findings from the analysis in a comprehensive conclusion, raises suggested solutions, and recommends further studies.

\section{Quality of aviation service}

Nowadays, customer satisfaction is regarded as one of the most indispensable elements playing a vital part in determining the success and prosperity of a specific business in such a dynamic and fast-growing market. According to Rust and Oliver [16], customer satisfaction is defined as an emotional or affective response which surfaces and develops when meeting with any kind of service. After service is provided, a positive or negative reaction will emerge from customers getting that service. Also, Oliver [13] stated that "customer satisfaction is the outcome of the evaluative process between the impression during or after service is performed and the expectations before experiencing the service." In specific situations, what people assume before using the service may contradict what we actually encounter during and after the service is performed.

In transportation context, the fact that passengers are satisfied with the services provided has a crucial effect on determining the long-term continuance of a specific carrier [15]. Dissatisfied passengers may lose their trust and not consider choosing the same airline again due to the bad service provided. Therefore, it is absolutely imperative for airlines to assure what customers expect and experience with their desired service quality [7].

The Draft International Standard, ISO/DIS 9000:2000, defines quality as "ability of a set of inherit characteristics of product, system, or process to fulfill requirements of customers and the other interested parties." Parasuraman et al. [14] argue that service quality is considered as results of customers' comparison between their expectation of the service and their perception after using the service. Tiernan et al. [19] and Namukasa [11] used the model of SERVQUAL [14] and SERVPERF [2] to examine the impact of airline service quality on passenger satisfaction.

Morash and Ozment [10] note that service quality conditions influence an airline's competitive advantage and with this comes market share and ultimately profitability. However, air transport service, like many other services, has its own characteristics and 
standards, about safety for example. Some characteristics are (i) interactive effects between service provider and customer, (ii) personalization, and (iii) high labor content.

According to the Australian Bureau of Transport Economics, standards of air transport service quality include (1) safety, (2) customer information, (3) flight frequency, (4) smooth air services, (5) on-time operation, (6) ground services and equipment, and (7) in-flight amenity and services. Elliott and Roach [3] suggest the following standards for aviation service: (1) food and beverages, (2) time for baggage collection, (3) comfortable seat, (4) checking procedure, and (5) in-flight services. Groundin and Kloppenborg [4] suggest a scale for aviation service quality including (1) baggage handling, (2) compensation procedure, (3) operation and safety, (4) flight comfort, and (5) network and flight frequency.

The McGraw-Hill Company [8] measures the service quality and satisfaction of 12,300 passengers of 12 North American airlines using the Skytrax standard suggested by Skyteam and finds seven influential factors: (1) fee, (2) in-flight service, (3) reservation, (4) flight crew, (5) boarding/deplaning/baggage, (6) aircraft, and (7) check-in.

\section{Relation between aviation service quality and customer satisfaction}

Ha and Nguyen [5] give a simple conclusion of customer satisfaction as an intersection or overlap area between corporate ability and customer need or a feeling of a person coming from comparison of outcome produced by commodity/service with his/her expectations.

Zeithaml and Bitner [20] argue that customer satisfaction with service quality is assessment and comparison of their perception of value of the service they receive with their expectation. Huang [6] says that many researches on aviation verify the relation between aviation service quality and customer satisfaction.

This research combines the findings from the abovementioned researches and applies modified criteria for measuring customer satisfaction with aviation service quality offered by McGraw-Hill [8] to the case of VNA in which aviation service quality comprises six determinants: (1) reservation (RES), (2) check-in (CHE), (3) aircraft (AIR), (4) in-flight services (INF), (5) flight crew (FLI), and (6) boarding/deplaning/baggage (BDB) (Additional file 1). The suggested research model is based on aforementioned theoretical preconditions and presented in Fig. 1, and the research hypotheses are stated as follows:

$\mathrm{H}_{1}$ : Reservation has the direct, positive impact on the VNA domestic passengers' satisfaction.

$\mathrm{H}_{2}$ : Check-in has the direct, positive impact on the VNA domestic passengers' satisfaction.

$\mathrm{H}_{3}$ : Aircraft has the direct, positive impact on the VNA domestic passengers' satisfaction.

$\mathrm{H}_{4}$ : In-flight service has the direct, positive impact on the VNA domestic passengers' satisfaction.

$\mathrm{H}_{5}$ : Flight crew has the direct, positive impact on the VNA domestic passengers' satisfaction.

$\mathrm{H}_{6}$ : Boarding/deplaning/baggage has the direct, positive impact on the VNA domestic passengers' satisfaction. 


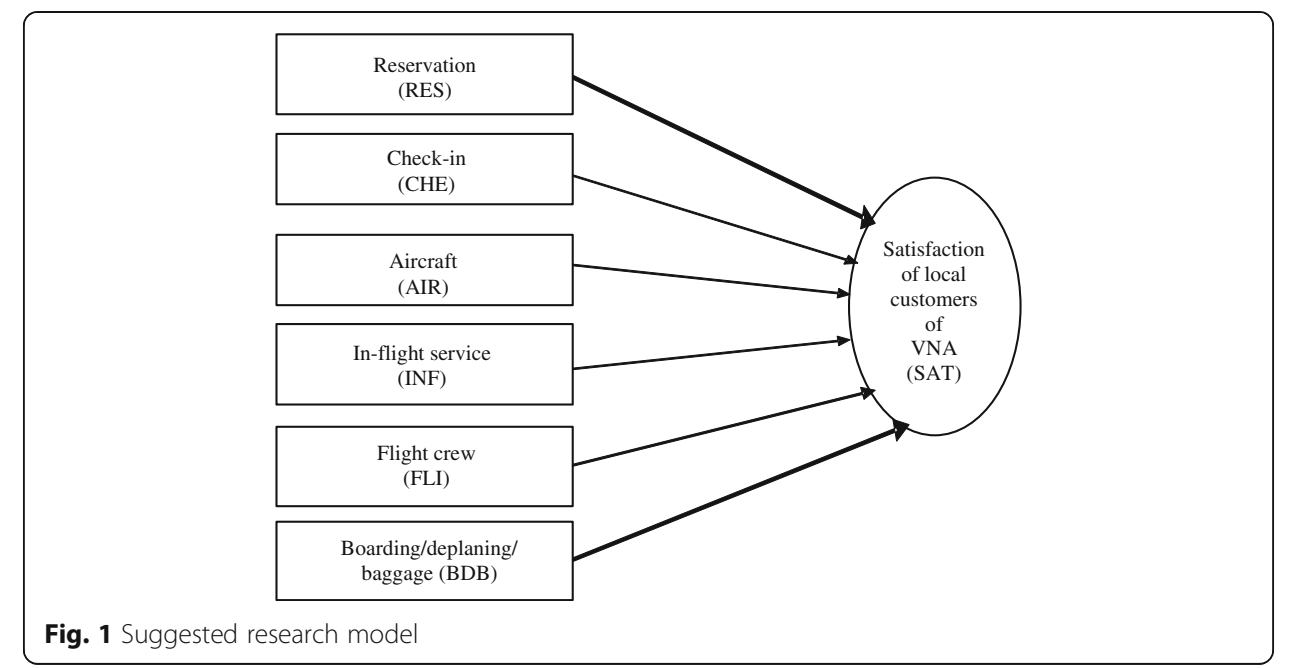

\section{Methods}

\section{Population and sampling}

The sample identified in this study was drawn from a population size of 28 million passengers in 2016. The intended sampling method is quota sampling. The sample size and sampling result are presented in Table 1. It has been found that sample sizes larger than 30 and less than 500 are appropriate for most research [17].

\section{Qualitative research}

In-depth interviews with three high-ranking VNA officials are conducted to identify determinants of service quality and evaluating criteria. Questions are devised beforehand. The interviewers are followed by a group discussion based on open questions with seven passengers who frequently use VNA domestic services in order to find their perception of determinants of service quality. Their opinions are used for improving and developing scales for aviation service quality.

\section{Data gathering}

A structured questionnaire with 5-point Likert scales with anchors "strongly disagree" to "strongly agree" was used in this study. Since 5-point Likert scales are widely used, especially in a business context, this research felt that it was appropriate to use the same tactic for this study. The questionnaire consisted of two parts. The first part was to examine the customer satisfaction through the variables of service quality. The second part was designed to collect respondents' demographic information. To validate

Table 1 Sample size and sampling result

\begin{tabular}{llll}
\hline Route & Quota & Interviewed passengers & Qualified responses \\
\hline TPHCM (SGN)-HaNoi (HAN) & 160 & 200 & 163 \\
TPHCM (SGN)-NhaTrang (NHA) & 120 & 150 & 122 \\
TPHCM (SGN)-DaNang (DAN) & 120 & 150 & 117 \\
Total & 400 & 500 & 402 \\
\hline
\end{tabular}


the questionnaire, a pilot test was carried out on a convenient sample of 30 passengers and the collected data was used to refine the survey instrument.

A quantitative survey is conducted in Tan Son Nhat Airport. The target population includes Vietnamese passengers who are in the 18-60 age bracket and used VNA domestic services two times at least in the last 6 months. To motivate the respondents, along with each questionnaire, a ball pen was distributed as a takeaway souvenir.

\section{Data analysis}

After collecting the data, a statistical package for social sciences (SPSS, 22 versions) was used for analyzing the data. Cronbach's alpha and exploratory factor analysis (EFA) were employed to test the reliability and validity, and then multiple regression analysis was performed to test the hypotheses. Subsequently, the tests of regression assumptions and difference tests consolidated the findings.

\section{Results and discussion}

\section{Characteristics of sample}

Data are gathered by 15-min direct interviews and questionnaires. The interviews are conducted at waiting lounges of airports. Out of 500 issued questionnaires, 437 (87.4\%) responded and 35 of them considered as inappropriate because of many wrong answers or unfilled blanks. Thus, only 402 answered questionnaires can be used for the research. The characteristics are presented in Table 2.

Table 2 Sample characteristics

\begin{tabular}{llll}
\hline & N $=402$ & Frequency & Percentage \\
\hline Gender & Male & 193 & 48.0 \\
Age & Female & 209 & 52.0 \\
& From 18 to 33 years old & 203 & 50.5 \\
& $\geq 34-46$ years old & 129 & 32.1 \\
Income & $\geq 47-60$ years old & 70 & 17.4 \\
& $\leq 5$ million VND/month & 84 & 20.9 \\
Purpose & 5-10 million VND/month & 208 & 51.7 \\
& $\geq 10$ million VND/month & 110 & 27.4 \\
& Business & 125 & 31.1 \\
& Conference & 39 & 9.7 \\
& Visiting relatives & 91 & 22.6 \\
& Tourism & 113 & 28.1 \\
& Other & 34 & 8.5 \\
& Secondary school & 23 & 5.7 \\
& High school & 73 & 18.2 \\
& Vocational & 45 & 11.2 \\
& College & 38 & 9.5 \\
& University & 151 & 37.6 \\
& Postgraduate & 72 & 17.9 \\
\hline
\end{tabular}




\section{Results of scale test}

Table 3 shows that Cronbach's alpha coefficients of all scales are greater than 0.6 and all item-total correlation coefficients are greater than 0.3 . Thus, all scales are reliable and can be used for EFA [12].

In the EFA process, principal determinant analysis and Varimax are employed. EFA results show that $\mathrm{KMO}=0.888$ while chi-square statistic of Barlett's test reaches 7298.249 at Sig. $=0.000$. All 31 determinants are reduced to seven factors with eigenvalue of 1.041 (greater than 1) with a variation of $66.42 \%$ (able to explain $66.42 \%$ of changes in dataset). Observed variables of seven factors all have factor loadings greater than 0.5 , and they are used for analyzing the research model of multiple linear regression. Thus, resultant scales are acceptable. After conducting the factor rotation with all 31 aforementioned variables, seven factors are extracted (Table 4).

EFA results show that scales measuring customer satisfaction and determinants of service quality did obtain convergent validity. The results also imply that the research model remains stable, comprising six independent variables and one dependent variable.

\section{Multiple linear regression analysis}

Table 5 shows that the dependent variable has a close linear relation with six independent variables at $\alpha<0.05$. Because all absolute correlation coefficients between variables vary from 0.245 to 0.671 , thus satisfying condition $-1 \leq r \leq+1$, all variables are qualified for multiple linear regression analysis. This demonstrates that the discriminant validity is achieved, or in other words, scales used in this research can measure various constructs. The correlation matrix also shows that the variable BDB has the greatest effect on the customer satisfaction while CHE produces the smallest effect.

Results of the MLR analysis of relations between factors of service quality and satisfaction using the Enter method are presented in Table 6. Relations between the aviation service quality reflected in six factors (INF, FLI, RES, CHE, BDB, and AIR) with satisfaction (SAT) all have Sig. greater than 0.05 , and they are presented in the following:

$$
\begin{aligned}
\mathrm{SAT}=0.3794 & \times \mathrm{BDB}+0.541 \times \mathrm{INF}+0.275 \times \mathrm{RES}+0.133 \times \mathrm{FLI}+0.483 \times \mathrm{CHE}+0.128 \\
& \times \mathrm{AIR}+0.241
\end{aligned}
$$

It turns out that all hypotheses are supported. Adjusted $R^{2}=0.627, F=113.414$, and Sig. $=0.000$. Table 6 shows that the greatest effect on SAT is produced by $\operatorname{BDB}(\beta=0.536)$,

Table 3 Cronbach's alpha coefficients for scales of determinants of quality service and customer satisfaction

\begin{tabular}{lllll}
\hline No. & Scale & $\begin{array}{l}\text { Number of observation } \\
\text { variables }\end{array}$ & $\begin{array}{l}\text { Cronbach's } \\
\text { alpha }\end{array}$ & $\begin{array}{l}\text { Smallest item total } \\
\text { correlation coefficients }\end{array}$ \\
\hline 1 & Reservation (RES) & 5 & 0.837 & 0.574 \\
2 & Check-in (CHE) & 3 & 0.733 & 0.517 \\
3 & Aircraft (AIR) & 3 & 0.654 & 0.378 \\
4 & In-flight services (INF) & 6 & 0.869 & 0.594 \\
5 & Flight crew (FLI) & 4 & 0.820 & 0.546 \\
6 & Boarding/deplaning/baggage (BDB) & 7 & 0.899 & 0.703 \\
7 & Satisfaction (SAT) & 3 & 0.834 & 0.656 \\
\hline
\end{tabular}


Table 4 EFA results

\begin{tabular}{lllll}
\hline No. & Factor & No. of variables & Eigenvalue & Variance extracted \\
\hline 1 & Boarding/deplaning/baggage (BDB) & 7 & 11.141 & 35.940 \\
2 & In-flight services (INF) & 6 & 2.111 & 6.811 \\
3 & Flight crew (FLI) & 4 & 2.003 & 6.460 \\
4 & Reservation (RES) & 5 & 1.694 & 5.465 \\
5 & Check-in (CHE) & 3 & 1.347 & 4.346 \\
6 & Aircraft (AIR) & 3 & 1.254 & 4.044 \\
7 & Satisfaction (SAT) & 3 & 1.041 & 3.357 \\
\hline
\end{tabular}

followed by CHE $(\beta=0.419)$, INF $(\beta=0.329)$, RES $(\beta=0.164)$, AIR $(\beta=0.158)$, and FLI $(\beta=0.106)$. Additionally, all regression coefficients bear positive signs, implying that all factors in the model are directly proportional to customer satisfaction.

Table 7 shows that $R^{2}$ is 0.633 and adjusted $R^{2}$ is 0.627 . This implies that the fitness of the model is $62.7 \%$. In other words, $62.7 \%$ of customer satisfaction can be explained by the sic independent variables, and the remaining $37.3 \%$ is affected by other variables.

Results of analysis of variance show that the $F$ value is 113.414 and Sig. $=0.000<0.01$ (Table 8), implying that at least one independent variable has a linear relation with the dependent variable. Thus, independent variables in the model have linear relations with the dependent variable and explain its changes; that is, determinants of service quality can explain changes in satisfaction. This means that the regression model is fit for dataset and usable, and all variables are statistically significant at $5 \%$.

Table 6 shows that tolerance value is very small and all VIF coefficients are smaller than 10, implying that multi-collinearity does not exist. Scatter plot of residual and predicted value of the regression model reveals no relation between them, and thus, the linearity assumption of the model is acceptable. In the result of analysis of residual based on histogram approximates-the standard level, the residual has a mean value $3.32 \times 10 \approx 0$ and std. dev. $=0.992 \approx 1$. P-P plot shows that distribution of the residual can be considered as standard, and assumption of normal distribution of residual is not violated. In short, results of model tests and tests for violation of necessary assumptions show that the regression model used in the research is suitable (Additional file 2).

\section{Difference testing}

All the difference tests can be found in Additional file 3. Independent samples $T$ test was used to test the satisfaction by gender. The result shows that Levene's Test for

Table 5 Correlation coefficients between determinants

\begin{tabular}{llllllll}
\hline & 1 & 2 & 3 & 4 & 5 & 6 & 7 \\
\hline Boarding/deplaning/baggage (BDB) & 1 & $.580^{* *}$ & $.517^{* *}$ & $.322^{* *}$ & $.245^{* *}$ & $.427^{* *}$ & $.671^{* *}$ \\
In-flight services (INF) & $.580^{* *}$ & 1 & $.493^{* *}$ & $.300^{* *}$ & $.299^{* *}$ & $.433^{* *}$ & $.566^{* *}$ \\
Flight crew (FLI) & $.517^{* *}$ & $.493^{* *}$ & 1 & $.411^{* *}$ & $.337^{* *}$ & $.393^{* *}$ & $.454^{* *}$ \\
Reservation (RES) & $.322^{* *}$ & $.300^{* *}$ & $.411^{* *}$ & 1 & $.159^{* *}$ & $.194^{* *}$ & $.272^{* *}$ \\
Check-in (CHE) & $.245^{* *}$ & $.299^{* *}$ & $.337^{* *}$ & $.159^{* *}$ & 1 & $.322^{* *}$ & $.555^{* *}$ \\
Aircraft (AIR) & $.427^{* *}$ & $.433^{* *}$ & $.393^{* *}$ & $.194^{* *}$ & $.322^{* *}$ & 1 & $.423^{* *}$ \\
Satisfaction (SAT) & $.671^{* *}$ & $.566^{* *}$ & $.454^{* *}$ & $.272^{* *}$ & $.555^{* *}$ & $.423^{* *}$ & 1 \\
\hline
\end{tabular}

" correlation is significant at the 0.01 level (2-tailed) 
Table 6 MLR analysis results

\begin{tabular}{|c|c|c|c|c|c|c|c|}
\hline \multirow[t]{2}{*}{ Model } & \multicolumn{2}{|c|}{ Unstandardized coefficients } & \multirow{2}{*}{$\begin{array}{l}\text { Standardized coefficients } \\
\beta\end{array}$} & \multirow[t]{2}{*}{$t$} & \multirow[t]{2}{*}{ Sig. } & \multicolumn{2}{|c|}{ Multicollinearity } \\
\hline & $B$ & Standard error & & & & Tolerance & VIF \\
\hline Constant & .241 & .197 & & 1.223 & .817 & & \\
\hline BDB & .794 & .045 & .536 & 17.642 & .000 & .569 & 1.758 \\
\hline INF & .541 & .050 & .329 & 10.826 & .000 & .579 & 1.727 \\
\hline RES & .275 & .051 & .164 & 5.384 & .000 & .591 & 1.693 \\
\hline FLI & .133 & .038 & .106 & 3.496 & .001 & .811 & 1.234 \\
\hline CHE & .483 & .035 & .419 & 13.791 & .000 & .835 & 1.198 \\
\hline AIR & .218 & .042 & .158 & 5.185 & .000 & .721 & 1.388 \\
\hline
\end{tabular}

Equality of Variances has Sig. $=0.037(<0.05)$, so Sig. of $T$ test at equal variances not assumed was used. $T$ test of $0.561>0.05$ shows that means of two samples are equal; it confers that there is no difference between male and female passengers of satisfaction.

Test of homogeneity of variances shows that the Levene statistic equals to 1.744 and Sig. $=0.160(>0.05)$, the variances between age groups are equal, and ANOVA could be used. ANOVA shows that $F=1.556$ and Sig. $=0.202(>0.05)$; it confers that there is no difference among age groups of satisfaction.

Test of homogeneity of variances shows that the Levene statistic equals to 0.865 and Sig. $=0.461(>0.05)$, the variances between age groups are equal, and ANOVA could be used. ANOVA shows that $F=1.403$ and Sig. $=0.244(>0.05)$; it confers that there is no difference among monthly income of satisfaction.

Test of homogeneity of variances shows that the Levene statistic equals to 5.474 and Sig. $=0.001(<0.05)$, the variances between age groups are unequal, and one-way ANOVA could not be used. Welch test [9] shows that $F=15.705$ and Sig. $=0.000(<0.05)$; it confers that there is difference among purpose of passengers about satisfaction.

Test of homogeneity of variances shows that the Levene statistic equals to 3.102 and Sig. $=0.028(<0.05)$, the variances between age groups are unequal, and one-way ANOVA could not be used. Welch test shows that $F=1.288$ and Sig. $=0.288(>0.05)$; it confers that there is no difference among education of passengers about satisfaction.

\section{Conclusions}

\section{Suggested solutions}

Results of estimation of determinants of aviation service according to statistic method describing the mean value in a 5-scale Likert show that scores given by passengers vary from "medium" to "pretty good" (Table 9). The highest scores are given to reservation (mean $=3.60)$, followed by in-flight services (3.56) and flight crew (3.51), while medium scores are given to aircraft (3.47) and boarding/deplaning/baggage (3.40) and the lowest one to check-in (3.31); SAT is given a pretty high score of 3.41. Based on those results,

Table 7 Adjusted $R^{2}$ and $F$ values

\begin{tabular}{|c|c|c|c|c|c|c|c|c|c|}
\hline \multirow[t]{2}{*}{ Model } & \multirow[t]{2}{*}{$R$} & \multirow[t]{2}{*}{$R^{2}$} & \multirow[t]{2}{*}{ Adjusted $R^{2}$} & \multirow{2}{*}{$\begin{array}{l}\text { Standard error } \\
\text { of the estimate }\end{array}$} & \multicolumn{5}{|c|}{ Statistical Changes } \\
\hline & & & & & $R^{2}$ change & F change & $\mathrm{df1}$ & $\mathrm{df} 2$ & Sig. $F$ change \\
\hline 1 & $.795^{\mathrm{a}}$ & .633 & .627 & .55298 & .633 & 113.414 & 6 & 395 & .000 \\
\hline
\end{tabular}


Table 8 Results of analysis of variance

\begin{tabular}{lllllll}
\hline Model & & Total sum of squares & df & Mean square & $F$ & Sig. \\
\hline 1 & Regression & 208.085 & 6 & 34.681 & 113.414 & $.000^{a}$ \\
& Residual & 120.787 & 395 & .306 & & \\
& Total & 328.872 & 401 & & & \\
\hline
\end{tabular}

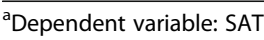

we can suggest some solutions to the management of VNA of how to enhance the customers' satisfaction.

For boarding/deplaning/baggage, flight schedule, especially for domestic services, should be preserved. Passengers should be informed timely of all changes or delays. Baggage delivery and collection should be done conveniently, and all damage to baggage should be handled and compensated properly. VNA must apply necessary services to passengers of delayed or canceled flights, such as some fee services in waiting lounges and hotel rooms at reasonable charges.

For check-in, VNA staff should service passengers with professionalism to avoid mistakes. More training courses in foreign languages and work ethics should be given to VNA staff to create a friendly atmosphere for passengers. For in-flight services, it can be improved by diversifying in-flight meals and entertainment programs and supplying more newspapers and magazines. Needed information about the flight should be given to the passengers. Air hostesses should be polite, considerate, and friendly towards passengers.

For reservation, VNA should respond properly when passengers want to change their reservation. Information about flight schedules should be available on the VNA website to spare customers from seeking information at travel agencies. VNA should supply online reservation services. For aircraft, VNA aircraft should have modern equipment to serve passengers better, especially children, pregnant women, and the disabled.

For flight crew, the pilot should have professional training and experience. The air crew should be friendly, considerate, and fluent in foreign languages. Knowledge of sign language also helps improve their communicative power.

Finally, VNA, as the national carrier with great financial and human potentials, along with support from local passengers, should make the best use of its advantages and favorable conditions to develop into an internationally acclaimed airline company.

\section{Future research}

It has been figured out that some adjustments could be done further to improve the quality of the research.

Table 9 Passengers' estimates of determinants

\begin{tabular}{lll}
\hline Factor & Mean & Standard deviation \\
\hline BDB & 3.40 & 1.032 \\
CHE & 3.31 & 1.054 \\
INF & 3.56 & .942 \\
RES & 3.60 & .897 \\
AIR & 3.47 & 1.009 \\
FLI & 3.51 & .990 \\
SAT & 3.41 & 1.045 \\
\hline
\end{tabular}


First of all, we should target a bigger sample size and more generalizable sampling method. This research is conducted based on a sample size of 402 passengers on the 03 domestic flights of SGN-HAN, SGN-NHA, and SGN-DAN, which certainly do not cover the whole population of passengers who traveled with VNA. Moreover, the majority of the targeted population was passengers who were waiting for their flights, so they somehow had been in a hurry or busy and not willing to fill in the questionnaire. Therefore, this can affect the reliability as well as the overall evaluation of the research.

Last but not least, many passengers would prefer to see VNA lower flight prices or discount programs to compete against competitors. Therefore, price should be considered as another important factor beside the current variables to increase the reliability and accuracy of the research.

\section{Conclusion}

The research identifies six determinants affecting the aviation service quality and customer satisfaction with VNA domestic services. The greatest effects are produced by BDB, followed by CHE, INF, RES, and AIR, and the weakest effect is caused by FLI. The six determinants can explain $62.7 \%$ of customer satisfaction. There is no difference of satisfaction between male and female passengers, among the age groups, among the monthly income groups, and among the education groups. The difference happens only among the passengers' purpose of travel, especially the high level of satisfaction appears with people who travel for business and conference; it may be rooted from the characteristics of on-time performance of VNA in comparison to the low-cost domestic airlines.

Statistics of mean values given by customers to those six determinants show that these values are not high. This implies that passengers are not really satisfied with VNA service. This research can be considered as a contribution to an empirical research on aviation service quality based on Skytrax standards.

\section{Additional files}

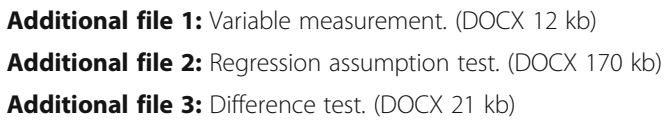

\section{Publisher's Note}

Springer Nature remains neutral with regard to jurisdictional claims in published maps and institutional affiliations.

Received: 9 May 2017 Accepted: 28 October 2017

Published online: 06 December 2017

\section{References}

1. Aksoy S., Atilgan E., \& Akinci S. (2003). Airline services marketing by domestic and foreign firms: differences from the customers' "viewpoint". J Air Transport Manag, 9, pp. 343-351

2. Cronin JJ, Taylor SA (1992) Measuring service quality: a reexamination and extension. J Mark 56:55-68

3. Elliott KM, Roach DW (1993) Service quality in the airline industry: are carriers getting an unbiased evaluation from consumers? J Prof Serv Mark 9:71-82

4. Groundin KN, Kloppenborg TJ (1991) Identifying service gaps in commercial air travel: the first step toward quality improvement. Transp J 1(1):22-30

5. Ha NKG, Nguyen TV (2011) Customer satisfaction on the service quality of the of Vinatex-mart chain. Econ Dev Rev 253:9-16 
6. Huang YK (2010) The effect of airline service quality on passengers' behavioral intentions using SERVQUAL score: a Taiwan case study. J Eastern Asia Society Transport Stud 8:2330-2343

7. Kossmann M (2006) Delivering excellent service quality in aviation: a practical guide for internal and external service providers. Ashgate Publishing Limited, England, p 2006

8. McGraw-Hill (2010) North American airline satisfaction. Manag Serv Qual 18(1):4-19

9. Moder, K. (2010). Alternatives to F-test in one way ANOVA in case of heterogeneity of variances (a simulation study). Psychol Test Assess Model, 52(4): 343-353

10. Morash WA, Ozment J (1994) Toward management of transportation service quality. Log Transport Review 30:115-140

11. Namukasa J (2013) The influence of airline service quality on passenger satisfaction and loyalty: the case of Uganda airline industry. TQM J 25(5):520-532

12. Nunnally J, Bernstein IH (1994) Pschychometric theory, 3rd edn. Irwin McGraw-Hill, New York

13. Oliver RL (1980) A cognitive model of the antecedents and consequences of satisfaction decisions. J Mark Res 49(Fall):41-50

14. Parasuraman A, Zeithaml VA, Berry LL (1985) A conceptual model of service quality and its implications for future research. J Mark 49:41-50

15. Rhea MJ, Shrock DL (1987) Measuring distribution effectiveness with key informant report. Log Transport Review 23(3):295-306

16. Rust TR, Oliver RL (1994) Service quality: insights and managerial implications from the frontier. Sage Publications, Thousand Oaks

17. Sekaran U (2003) Research methods for business: a skill-building approach, 4th edn. John Wiley \& Sons, Inc, New York

18. Skytrax (2010). Vietnam Airlines: official 3-star ranking of product and service quality, retrieved from www. airlinequality.com/Airlines/NN.htm, July 22, 2016

19. Tiernan S, Rhoades DL, Waguespack B (2008) Airline service quality-exploratory analysis of customer perceptions and operational performance in the USA and EU. Manag Serv Qual 8(3):212-224

20. Zeithaml VA, Bitner MJ (2001) Services marketing: integrating customer focus across the firms. Tata McGraw Hill, Boston

Submit your manuscript to a SpringerOpen ${ }^{\circ}$ journal and benefit from:

- Convenient online submission

- Rigorous peer review

Open access: articles freely available online

- High visibility within the field

Retaining the copyright to your article

Submit your next manuscript at $>$ springeropen.com 